Tropical Journal of Pharmaceutical Research June 2017; 16 (6): 1259-1266

ISSN: $1596-5996$ (print); 1596-9827 (electronic)

(C) Pharmacotherapy Group, Faculty of Pharmacy, University of Benin, Benin City, 300001 Nigeria.

All rights reserved.

Available online at http://www.tjpr.org

Original Research Article

http://dx.doi.org/10.4314/tjpr.v16i6.8

\title{
Mitochondrial transcription factor A protects human retinal endothelial cell injury induced by hypoxia
}

\author{
Qilian $\mathrm{Xie}^{1 \star}$ and $\mathrm{Xu} \mathrm{Cao}^{2}$ \\ ${ }^{1}$ Department of Ophthalmology, The First Affiliated Hospital, and College of Clinical Medicine of Henan University of Science \\ and Technology, Luoyang, Henan, 471003, ${ }^{2}$ Department of Electrocardiogram, Luoyang Central Hospital Affiliated to \\ Zhengzhou University, Luoyang, Henan, 471009, China
}

*For correspondence: Email: xql116@163.com; Tel: +0086 -379-64830609

Sent for review: 3 January 2017

Revised accepted: 20 May 2017

\begin{abstract}
Purpose: To investigate the impact of mitochondrial transcription factor A (TFAM), as a modulator of $N F-K B$, on proliferation of hypoxia-induced human retinal endothelial cell (HREC), and the probable mechanism.

Methods: After exposure to hypoxia $\left(1 \% \mathrm{O}_{2}\right)$ for 5 days, cell proliferation and cell cycle of HREC were measured by MTT (3- (4,5-dimethyl-2-thiazolyl)-2,5-diphenyl-2-H-tetrazolium bromide) assay and flow cytometry. Cell signaling and mitochondrial DNA (mtDNA) copies were determined using real-time polymerase chain reaction and Western blot. NF-KB activity was evaluated by luciferase assay.

Results: TFAM expression decreased to $40 \%$ in HREC under hypoxic condition $(p<0.05)$. MTT results revealed that TFAM facilitated HREC proliferation under hypoxia $(p<0.05)$. Moreover, flow cytometry demonstrated that TFAM promoted HREC proliferation by accelerating cell cycle $(p<0.05)$. Western blot and luciferase assay exhibited NF-KB activation in HREC after TFAM overexpression $(p<0.05)$. Finally, real-time PCR results showed that $m t D N A$ and targeted genes of NF- $K B$ were upregulated 3-fold in HREC after TFAM transfection under hypoxia $(p<0.05)$.

Conclusion: These results indicate that NF-KB activated by TFAM protects against hypoxia-induced HREC injury by accelerating cell cycle. The ability of TFAM to enhance NF-KB signaling may be part of the mechanism of hypoxia-induced cell injury. Thus, upregulation of TFAM may help to relieve diabetic retinopathy.
\end{abstract}

Keywords: Mitochondrial transcription factor A, NF-KB, Hypoxia, Human retinal endothelial cell, Diabetic retinopathy

Tropical Journal of Pharmaceutical Research is indexed by Science Citation Index (SciSearch), Scopus, International Pharmaceutical Abstract, Chemical Abstracts, Embase, Index Copernicus, EBSCO, African Index Medicus, JournalSeek, Journal Citation Reports/Science Edition, Directory of Open Access Journals (DOAJ), African Journal Online, Bioline International, Open-J-Gate and Pharmacy Abstracts

\section{INTRODUCTION}

Endothelium dysfunction plays an important role in the development of vascular complications in diabetes [1]. Premature death of the capillary components, including endothelial cell and pericytes, occurs during the vasodegenerative stage of diabetic retinopathy [2]. The injury of retinal microvessels induced by diabetes results in the features of diabetic retinopathy, such as blood-retinal barrier leakage, non-perfusion capillary formation, and neovascularization [3]. Hypoxia is an important factor for the pathogenesis of human retinal endothelial cell (HREC) injury, which may promote intraocular neovascularization via imbalancing angiogenic homeostasis under physiological conditions [4,5]. However, the precise mechanism by which hypoxia affects HREC proliferation still needs further elucidation.

Retinal mitochondria are compromised in 
diabetes, leading to mitochondrial DNA (mtDNA) damage [6]. As mtDNA is extremely important in the electron transport chain, it plays a critical role in regulating superoxide and apoptosis $[7,8]$. Mitochondrial transcription factor A (TFAM), as one of the key factors that binds to the regulatory area of mtDNA, activate the transcription of the target proteins of mtDNA [9].

TFAM gene expression was found to be increased, while its protein level was unchanged in diabetic retina [10]. However, mitochondrial protein levels are reduced in diabetes. Mitochondrial dysfunctional and mtDNA damage are still not alleviated even after recovery of normal glycemic condition in diabetic rats [11]. Thus, it was postulated that TFAM may regulate metabolic disorder of retina through posttranscriptional modification. Its influence on cell proliferation under hypoxia condition also needs further investigation.

NF-KB plays key roles in numerous cellular, even in physiological, and pathological processes, as a multi-faceted transcription factor. [12-14]. Traditionally, NF-KB is a central mediator in immune and inflammatory responses [14], and it also participates in the progression of cancer [15]. The anti-apoptotic and proliferative functions of NF-KB in parenchymal cells facilitate repair of organ [16], whereas it can accelerate inflammation in macrophages and other inflammatory cells $[13,14]$. In addition, NF-KB is involved in energy balance [17] and tissue homeostasis [18]. Although the functions of NF$\mathrm{KB}$ in inflammation and cancer have been widely explored [19], its potential role in diabetic retinopathy. Since diabetic retinopathy is significantly related to retinal endothelial cell injury, NF-KB may participate in regulating HREC proliferation and cell cycle in diabetic retinopathy, in which it has not been investigated the underlying function of NF-KB. Herein, we aimed to explore if TFAM regulate hypoxia induced retinal endothelial cell injury through the NF-KB signaling pathway.

\section{EXPERIMENTAL}

\section{Cell culture and hypoxia condition}

HREC was purchased from American Type Culture Collection (ATCC, USA). DMEM medium was used for maintaining the cells supplemented with $10 \%$ fetal calf serum, streptomycin $(0.1$ $\mathrm{mg} / \mathrm{mL})$ and penicillin $(100 \mathrm{U} / \mathrm{mL})$ at $5 \% \mathrm{CO}_{2}$ and $37{ }^{\circ} \mathrm{C}$. Normal incubators with $21 \% \mathrm{O}_{2}$ were applied as the normoxic condition. Incubators with $1 \% \mathrm{O}_{2}, 5 \% \mathrm{CO}_{2}$, and $94 \% \mathrm{~N}_{2}$ were used for hypoxic cultures.

\section{MTT assay}

The HREC were seeded in 96-well plate at $2 \times$ $10^{3}$ cells/well. Cells were then transfected with by TRAM or TRAM siRNA for $24 \mathrm{~h}$. During the last 4 $\mathrm{h}$ of each day of culture, cells were treated with MTT (at $50 \mathrm{mg}$ per well (Sigma, St. Louis, MO). The formazan was dissolved with dimethyl sulfoxide (DMSO) for $30 \mathrm{~min}$ and a microplate reader (Bio-tek, Winooski, VT) was used to measure the absorbance at $450 \mathrm{~nm}$.

\section{Cell cycle analysis}

HREC cells were collected and washed three times with PBS. The cells were fixed in $70 \%$ precooled ethanol $(1 \mathrm{~mL})$ at $4{ }^{\circ} \mathrm{C}$ overnight. Next, the cells were washed with PBS and incubated in RNase $(100 \mu \mathrm{g} / \mathrm{mL})$ at $37{ }^{\circ} \mathrm{C}$ for $0.5 \mathrm{~h}$. After staining with $\mathrm{PI}(50 \mu \mathrm{g} / \mathrm{mL})$ at $4{ }^{\circ} \mathrm{C}$ for $30 \mathrm{~min}$ in the dark, flow cytometry was used to analyze the cell cycle at $488 \mathrm{~nm}$. The primary result was analyzed with FlowJo software to acquire the hypodiploid peak, so as to calculate the cell ratio in $\mathrm{G} 0 / \mathrm{G} 1$ phase, $S$ phase, and G2/M phase, respectively. All the experiments were repeated three times.

\section{Real-time PCR}

TaKaRa MiniBEST universal RNA Extraction Kit (Takara, Japan) was used to extracted the total RNA. RNA was eluted in $50 \mathrm{~mL}$ of RNase-free water and preserved at $-70^{\circ} \mathrm{C}$. To analyze gene expression, real-time PCR mixture system containing primers, cDNA templates, and SYBR Green qPCR Master Mix were reacted using real-time PCR according to standard methods. Fold changes in gene expression were calculated upon $2^{-} \Delta \Delta^{\mathrm{Ct}}$ method with as an internal control of GAPDH.

\section{Determination of mitochondrial DNA (mtDNA) copy number}

Quantification of mitochondrial DNA was operating as a previously reported method with minor modifications [20]. The PAGE-purified synthetic oligonucleotide standard (Integrated DNA Technologies, Coralville, IA) was diluted using $\mathrm{TE}^{-4}$ to generate standards. The amplification reactions consisted template DNA $(1 \mu \mathrm{L})$ at a final volume of $25 \mu \mathrm{L}$. All qPCR experiments consisted minimally of each quantification standard in duplicate, a TE-4 notemplate control, and an HL-60 DNA-positive control. 


\section{Western blot analysis}

HREC cells were lysed with loading lysis buffer that was diluted from $5 \times$ loading lysis buffer (2.5 $\mathrm{mL}$ Tris $-\mathrm{HCl}$ at $0.5 \mathrm{M}, 0.39 \mathrm{~g}$ dithiothreitol, $0.5 \mathrm{~g}$ sodium dodecyl sulfate, $0.025 \mathrm{~g}$ bromophenol blue, and $2.5 \mathrm{~mL}$ glycerin). Equal amount of protein was transferred to the polyvinylidene fluoride (PVDF) membrane. Next, the membrane was blocked with skimmed milk and further incubated in primary antibodies at $4{ }^{\circ} \mathrm{C}$ for $1 \mathrm{~h}$. After incubation with horseradish peroxidase (HRP)-conjugated secondary antibodies, in the binding signals were visualized with enhanced chemiluminescence (Thermo Fisher Scientific, UK).

\section{Cell transfection}

Cells were transfected by Lipofectamine 2000 transfection reagent (Invitrogen) according to the manual. For the gene expression analyses, cells were transfected with plasmid DNA (1 $\mu \mathrm{g} /$ well); TFAM (50 ng) or TFAM siRNA, pDUO-hMD2/CD14 (300 ng) adjusted with pcDNA3.1 to 1 $\mu \mathrm{g}$. The total plasmid load was adjusted to $1 \mu \mathrm{g}$ plasmid DNA with pcDNA3.1.

\section{Luciferase assay}

Cells were seeded in 24-well plate. then transfected with TFAM plasmid or siRNA.48 $\mathrm{h}$ later, the cells were transfectedwith $0.5 \mu \mathrm{g} \mathrm{NF-KB}$ reporter (GeneCopoeia, China) and $10 \mathrm{ng} \mathrm{pRL}-$ TK plasmids (Promega, WI) using EndoFectin ${ }^{\mathrm{TM}}$ Plus. These were performed according to the dual-luciferase assay specifications (Promega, US) using the Lucetta ${ }^{\mathrm{TM}}$ Luminometer (Lonza, Swiss). The transfection efficiency was measured by the normalized activity of firefly luciferase to the. All of the experiment were repeated 3 times.

\section{Statistical analysis}

All data analyses were carried out with SPSS 18.0 software. The data are presented as mean \pm standard (SD) and compared by t-test or oneway ANOVA. $P<0.05$ was considered statistically significant.

\section{RESULTS}

\section{Down-regulation of TFAM expression in hypoxia treated HREC}

To compare the mRNA expression of TFAM in HREC cells from the normal culture and hypoxic culture, cells were subjected to real-time PCR. The results showed that TFAM mRNA significantly increased in the hypoxic group (Figure 1A). Furthermore, it was found that TFAM mRNA level gradually reduced in HREC under hypoxic environment following time extension (Figure 1B).

\section{TFAM transfection enhanced HREC proliferation}

Since TFAM was downregulated in HREC under hypoxia environment, we proposed that TFAM was involved in regulating HREC behavior. HREC cells were transfected with TFAM plasmid and incubated under hypoxia environment. The result of Real-time PCR showed that TFAM mRNA was significantly overexpressed in HREC cells after TFAM transfection (Figure 2A). MTT assay revealed that TFAM upregulation enhanced HREC cell proliferation under hypoxia condition (Figure 2B).
A

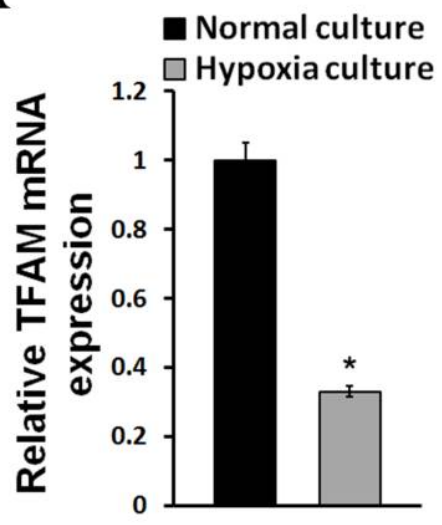

B

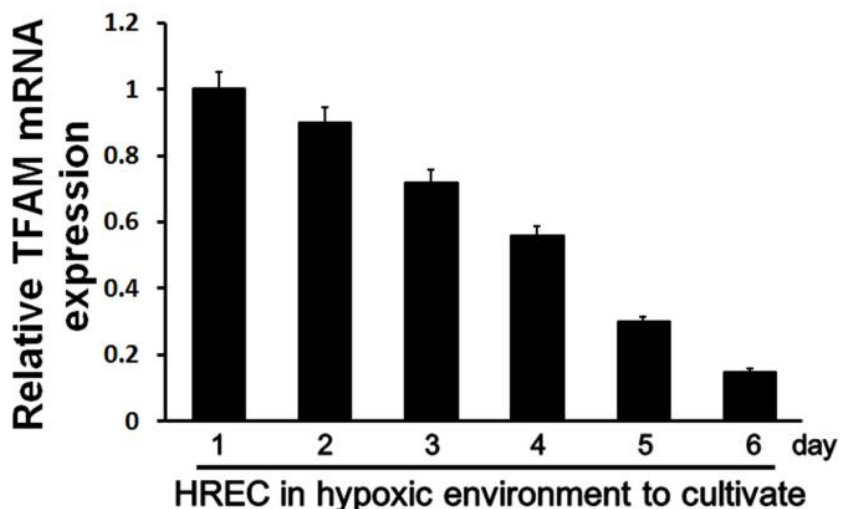

Figure 1: TFAM downregulated in HREC under hypoxia. (A) TFAM mRNA expression in HREC under hypoxic and normoxic culture. (B) TFAM mRNA expression in HREC cultured in hypoxia at different times; ${ }^{*} p<0.05$, compared with control 
A

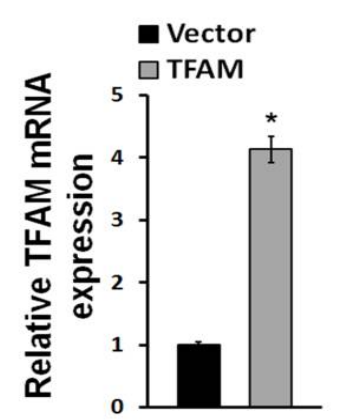

B

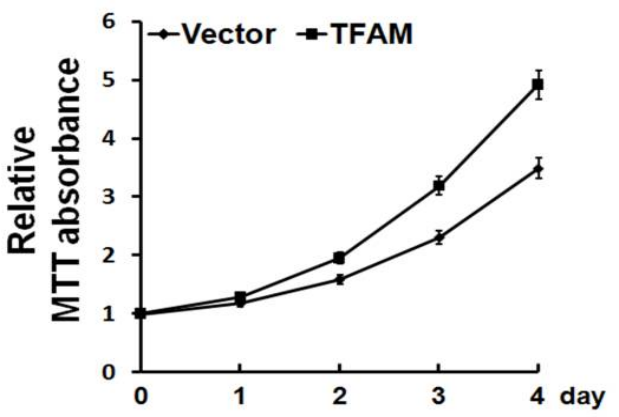

$\mathrm{D}$

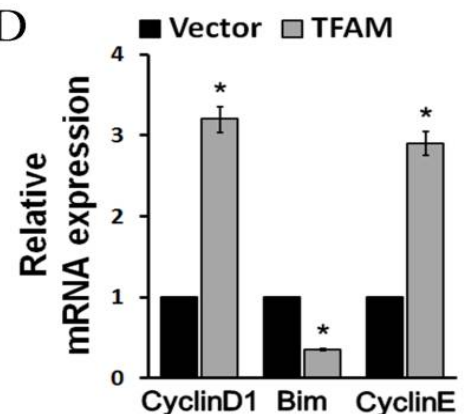

Figure 2: TFAM facilitated HREC cell proliferation and cell cycle. (A) TFAM mRNA expression in HREC after TFAM transfection. (B) HREC cell proliferation detected with MTT assay after TFAM transfection. (C) HREC cell cycle determined by flow cytometry after TFAM transfection. (D) Cell proliferation and cell cycle related gene expressions in HREC tested by real-time PCR after TFAM transfection; ${ }^{*} p<0.05$, compared with control

Flow cytometry demonstrated that TFAM transfection apparently accelerated HREC cell cycle compared with control (Figure 2C). Also, cell cycle related molecules Cyclin D1 and Cyclin $E$ were found to be markedly increased, while apoptotic factor Bim decreased in HREC after TFAM transfection.

\section{TFAM inhibition blocked HREC proliferation}

To further analyze the effect of TFAM in HREC cell proliferation and cell cycle, we adopted TFAM siRNA to downregulate TFAM level. It was found that TFAM mRNA was significantly reduced in HREC transfected by TFAM siRNA (Figure 3A). Moreover, HREC cell proliferation was inhibited by TFAM siRNA under hypoxic condition (Figure 3B). HREC cell cycle was blocked in G0/G1 phase by TFAM interference in hypoxia group (Figure 3C). Cyclin D1 and Cyclin $\mathrm{E}$ were markedly downregulated, whereas Bim was enhanced in HREC after TFAM interference (Figure 3D).

\section{TFAM regulated NF-KB signaling in HREC} under hypoxia condition

To investigate the specific mechanism of TFAM in regulating HREC cell proliferation, real-time PCR results showed that mtDNA copy number was significantly elevated in HREC transfected by TFAM, while TFAM siRNA showed the opposite effect (Figure 4A). Western blot demonstrated that p65 protein level in HREC nucleus was enhanced in the TFAM transfection group compared with control. TFAM siRNA apparently suppressed p65 protein expression in HREC nucleus (Figure 4B). Luciferase assay showed that the activity of NF-KB was activated in HREC transfected by TFAM, suggesting the regulatory role of TFAM on NF-KB signaling pathway (Figure 4C). Multiple target genes of NF-KB signaling pathway, including MYC, FLIP, TNF, Bmil, and IL-8 were upregulated by TFAM, while they declined in HREC treated with TFAM siRNA (Figure 4D).

\section{DISCUSSION}

Retinal endothelial cell proliferation suppression is considered to be the hallmark of diabetic retinopathy, while mitochondria insufficiency plays a key role in facilitating retinal cell apoptosis [21]. In this study, we identified the protective role of TFAM in diabetic retinopathy by promoting HREC cell proliferation and cell cycle under hypoxic condition. We also observed that part of the acceleration effects of TFAM on HREC cell proliferation is mediated by regulating NF-KB signaling pathway. 
A

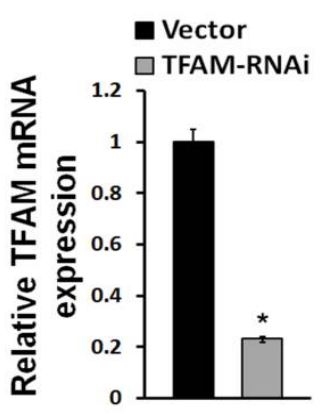

$\mathrm{C}$

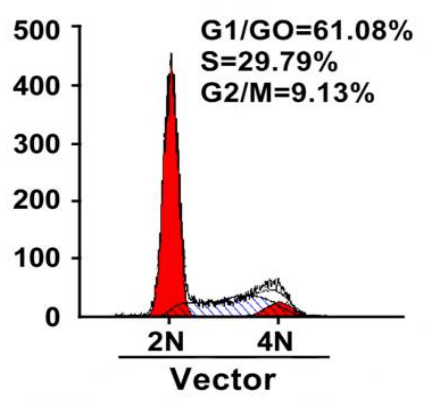

B
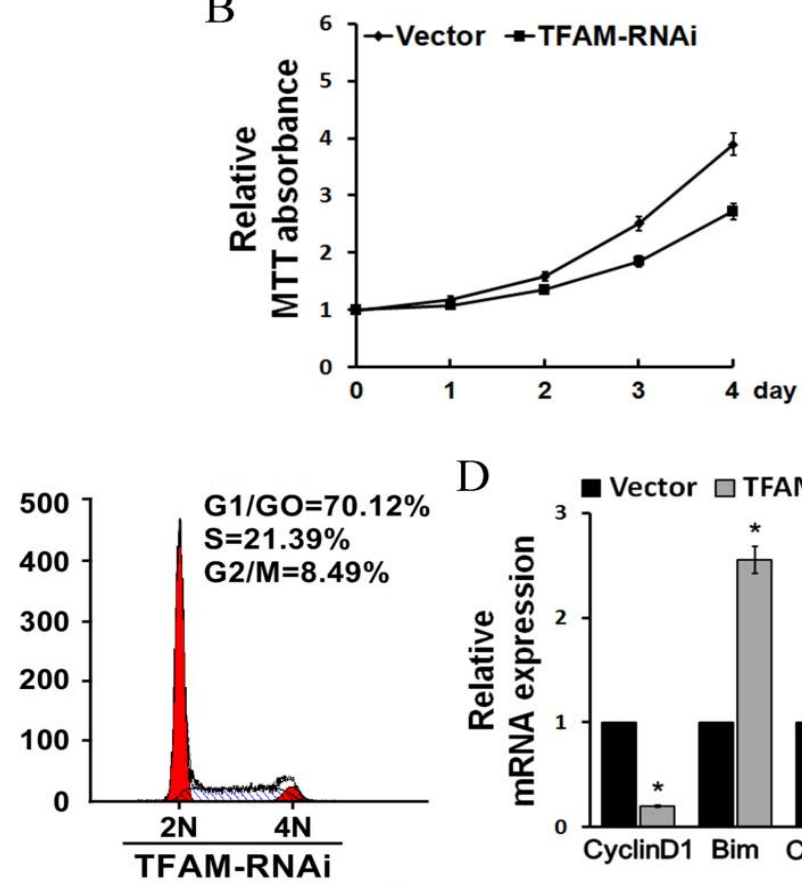

$\mathrm{D}$

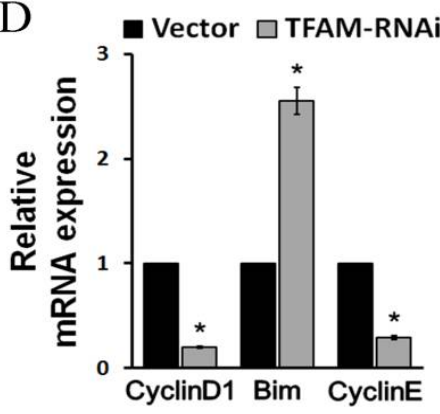

Figure 3: TFAM siRNA inhibited HREC cell proliferation and cell cycle. (A) TFAM mRNA expression in HREC after TFAM siRNA transfection. (B) HREC cell proliferation detected by MTT assay after TFAM siRNA transfection. (C) HREC cell cycle determined by flow cytometry after TFAM siRNA transfection. (D) Cell proliferation and cell cycle related gene expressions in HREC tested by real-time PCR after TFAM siRNA transfection; * $p<0.05$, compared with control

A

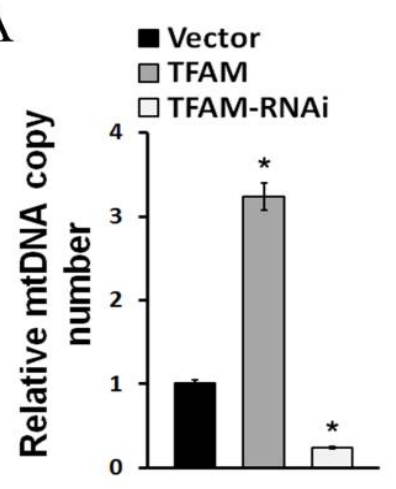

C

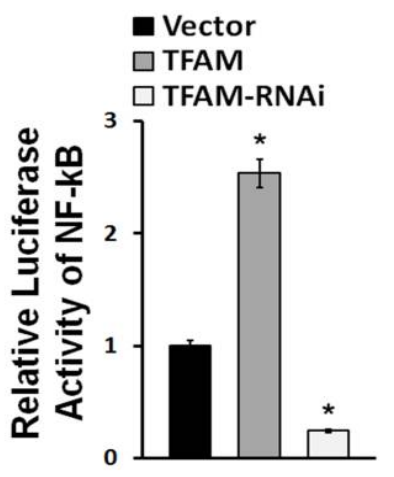

B
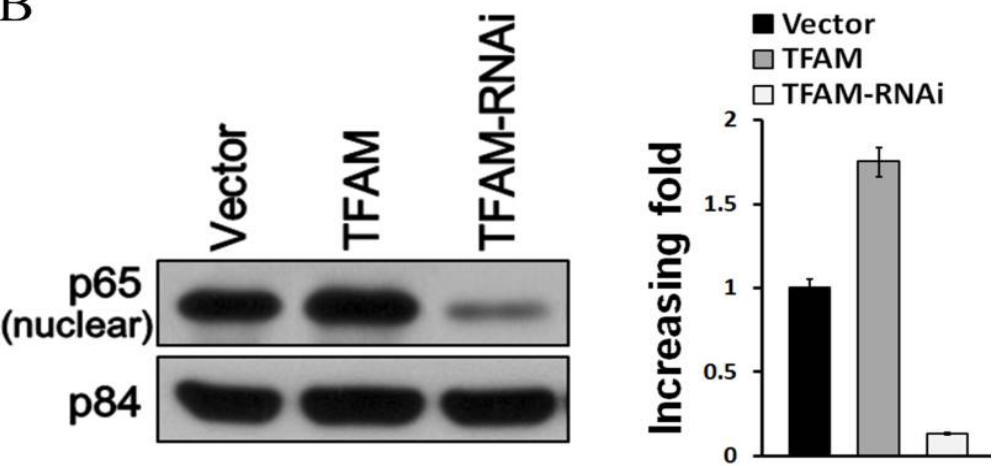

$\mathrm{D}$



Figure 4: TFAM regulated NF-KB signaling pathway in HREC. (A) mtDNA copy number in HREC assessed by real-time PCR. (B) Cellular nuclear p65 protein expression in HREC determined by Western blot. (C) NF-KB activity in HREC evaluated by luciferase assay. (D) Target gene expressions of NF-KB signaling pathway in HREC detected by real-time PCR; ${ }^{*} p<0.05$, compared with control 
Mitochondria are the initial consumers of oxygen. A variety of products of mitochondria have been shown to mediate the activity of HIF prolyl hydroxylases, such as TCA cycle intermediates, ROS, and oxygen consumption [22]. The importance of mitochondria as regulators of HIF signaling pathway, which is critical in hypoxia homeostasis, has been highly confirmed as numerous effective inhibitors of HIF activation were verified to be mitochondrial inhibitors [23]. By comparing HREC under normoxic and hypoxic conditions, we discovered that TFAM mRNA level was higher in hypoxic HREC than normal control. Moreover, it was also revealed that TFAM expression was gradually reduced in HREC stimulated by hypoxia following elongation of incubation time. Thus, we proposed that TFAM may be involved in the pathogenesis of diabetic retinopathy.

As a transcription factor for mitochondrial DNA, TFAM is required for replication and transcription of mtDNA. It has reported that TFAM is participate in the regulation of cell survival, proliferation and migration. For example, the proliferation of vascular smooth muscle cell is dependent on the upregulation of TFAM expression in injured rat carotid artery [24]. It has been proved that TFAM regulates p21 (WAF1/CIP1), which is a key regulator of cell cycle progression, since knockdown of TFAM expression would induce p21-dependent G1 cell cycle arrest [25]. Moreover, TFAM is participate in the development and progression of malignant tumors. In microsatellite-unstable colorectal cancer, frequent truncating mutation of TFAM induced depletion of mtDNA and apoptotic resistance [26]. However, the role of TFAM in HREC under hypoxic condition remains uncovered. In this study, we evaluated the impact of TFAM using MTT assay, flow cytometry, and real-time PCR. The results showed that TFAM overexpression promoted cell cycle and proliferation. On the contrary, TFAM siRNA led to cell cycle blockage and proliferation inhibition under hypoxia. These results supported the hypothesis that TFAM participates in cell proliferation in HREC.

We further identified the potential targets of TFAM, which we further verified by Western blot, luciferase assay, and real-time PCR. The results indicated that TFAM promoted NF-KB translocation into nucleus in HREC under hypoxic condition. Luciferase assay suggested that TFAM effectively enhanced the activity of NF-KB, which further verified the role of TFAM on NF-KB in hypoxic environment. Real-time PCR demonstrated that several target genes of NF-KB signaling pathway were upregulated by TFAM transfection in HREC, confirming the promoting effect of TFAM on NF-KB signaling pathway. NF$\mathrm{KB}$ transcription factor family regulates a large amount of genes involved in cell function and inflammation. NF-KB family proteins have been detected in diabetic retinopathy and participate in ganglion cell death, formation of epiretinal membranes, and angiogenesis [27-29]. Furthermore, TFAM was found to be involved in the protective role of astrocytes in protecting neurons through NF-kB signaling pathway, indicating the regulatory role of TFAM on NF-KB [30].

\section{CONCLUSION}

The findings of the study show that TFAM is downregulated in HREC under hypoxia. This mitochondrial modulator promotes NF-KB signaling pathway. Aberrant overexpression of TFAM in diabetic retinopathy causes increased NF-KB signaling pathway in HREC. This abnormal signaling further allows cells to promote proliferation and cell cycle, leading to the protection of retinal endothelial cells in diabetic retinopathy. These results provide new insight into diabetic retinopathy and a potential choice for diabetic retinopathy therapy, as TFAM activity clearly affects the critical mechanism in diabetic retinopathy progress.

\section{DECLARATIONS}

\section{Acknowledgement}

This research was supported by department funds.

\section{Conflict of Interest}

No conflict of interest associated with this work.

\section{Contribution of Authors}

The authors declare that this work was done by the authors named in this article and all liabilities pertaining to claims relating to the content of this article will be borne by them.

\section{Open Access}

This is an Open Access article that uses a funding model which does not charge readers or their institutions for access and distributed under the terms of the Creative Commons Attribution License (http://creativecommons.org/licenses/by/ 4.0) and the Budapest Open Access Initiative (http://www.budapestopenaccessinitiative.org/rea d), which permit unrestricted use, distribution, 
and reproduction in any medium, provided the original work is properly credited.

\section{REFERENCES}

1. Tooke JE, Goh KL. Vascular function in Type 2 diabetes mellitus and pre-diabetes: the case for intrinsic endotheiopathy. Diabet Med 1999; 16: 710-715.

2. Barber AJ. A new view of diabetic retinopathy: a neurodegenerative disease of the eye. Prog Neuropsychopharmacol Biol Psychiatry 2003; 27: 283290.

3. Tikhonenko M, Lydic TA, Opreanu M, Li Calzi S, Bozack $S$, McSorley KM, Sochacki AL, Faber MS, Hazra $S$, Duclos $S$, et al. N-3 polyunsaturated Fatty acids prevent diabetic retinopathy by inhibition of retinal vascular damage and enhanced endothelial progenitor cell reparative function. PLoS One 2013; 8: e55177.

4. Miller JW, Adamis AP, Aiello LP. Vascular endothelial growth factor in ocular neovascularization and proliferative diabetic retinopathy. Diabetes Metab Rev 1997; 13: 37-50.

5. Iruela-Arispe ML, Dvorak HF. Angiogenesis: a dynamic balance of stimulators and inhibitors. Thromb Haemost 1997; 78: 672-677.

6. Madsen-Bouterse $S$, Mohammad G, Kowluru RA. Glyceraldehyde-3-phosphate dehydrogenase in retinal microvasculature: implications for the development and progression of diabetic retinopathy. Invest Ophthalmol Vis Sci 2010; 51: 1765-1772.

7. Madsen-Bouterse SA, Zhong Q, Mohammad G, Ho YS, Kowluru RA. Oxidative damage of mitochondrial DNA in diabetes and its protection by manganese superoxide dismutase. Free Radic Res 2010; 44: 313-321.

8. Santos JM, Tewari S, Goldberg AF, Kowluru RA. Mitochondrial biogenesis and the development of diabetic retinopathy. Free Radic Biol Med 2011; 51: 1849-1860.

9. Scarpulla RC. Transcriptional paradigms in mammalian mitochondrial biogenesis and function. Physiol Rev 2008; 88: 611-638.

10. Santos JM, Kowluru RA. Role of mitochondria biogenesis in the metabolic memory associated with the continued progression of diabetic retinopathy and its regulation by lipoic acid. Invest Ophthalmol Vis Sci 2011; 52: 87918798.

11. Santos JM, Mishra M, Kowluru RA. Posttranslational modification of mitochondrial transcription factor $A$ in impaired mitochondria biogenesis: implications in diabetic retinopathy and metabolic memory phenomenon. Exp Eye Res 2014; 121: 168-177.

12. Perkins ND. Integrating cell-signalling pathways with NFkappaB and IKK function. Nat Rev Mol Cell Biol 2007; 8 49-62.

13. Ghosh S, Hayden MS. Celebrating 25 years of NFkappaB research. Immunol Rev 2012; 246: 5-13.
14. Liu SF, Malik AB. NF-kappa $B$ activation as a pathological mechanism of septic shock and inflammation. Am J Physiol Lung Cell Mol Physiol 2006; 290: L622-L645.

15. Rinkenbaugh AL, Baldwin AS. The NF-kappaB Pathway and Cancer Stem Cells. Cells 2016; 5.

16. Liu G, Ye $X$, Miller EJ, Liu SF. NF-kappaB-to-AP-1 switch: a mechanism regulating transition from endothelial barrier injury to repair in endotoxemic mice. Sci Rep 2014; 4: 5543.

17. Chiang SH, Bazuine $M$, Lumeng $C N$, Geletka LM, Mowers J, White NM, Ma JT, Zhou J, Qi N, Westcott D, et al. The protein kinase IKKepsilon regulates energy balance in obese mice. Cell 2009; 138: 961-975.

18. Pasparakis M. Regulation of tissue homeostasis by NFkappaB signalling: implications for inflammatory diseases. Nat Rev Immunol 2009; 9: 778-788.

19. Park MH, Hong JT. Roles of NF-kappaB in Cancer and Inflammatory Diseases and Their Therapeutic Approaches. Cells 2016; 5.

20. Sprouse ML, Phillips NR, Kavlick MF, Roby RK. Internal validation of human mitochondrial DNA quantification using real-time PCR. J Forensic Sci 2014; 59: 10491056.

21. Tewari S, Santos JM, Kowluru RA. Damaged mitochondrial DNA replication system and the development of diabetic retinopathy. Antioxid Redox Signal 2012; 17: 492-504.

22. Bell EL, Klimova TA, Eisenbart J, Moraes CT, Murphy $M P$, Budinger GR, Chandel NS. The Qo site of the mitochondrial complex III is required for the transduction of hypoxic signaling via reactive oxygen species production. J Cell Biol 2007; 177: 1029-1036.

23. Lin X, David CA, Donnelly JB, Michaelides M, Chandel NS, Huang $X$, Warrior U, Weinberg F, Tormos KV, Fesik SW, Shen Y. A chemical genomics screen highlights the essential role of mitochondria in HIF-1 regulation. Proc Natl Acad Sci U S A 2008; 105: 174-179.

24. Yoshida T, Azuma H, Aihara K, Fujimura M, Akaike M, Mitsui T, Matsumoto T. Vascular smooth muscle cell proliferation is dependent upon upregulation of mitochondrial transcription factor A (mtTFA) expression in injured rat carotid artery. Atherosclerosis 2005; 178: 39-47.

25. Kim AJ, Jee HJ, Song $N$, Kim $M$, Jeong $S Y$, Yun J. p21(WAF(1)/C(1)P(1)) deficiency induces mitochondrial dysfunction in HCT116 colon cancer cells. Biochem Biophys Res Commun 2013; 430: 653-658.

26. Guo J, Zheng L, Liu W, Wang X, Wang Z, Wang Z, French $A J$, Kang $D$, Chen L, Thibodeau SN, Liu W. Frequent truncating mutation of TFAM induces mitochondrial DNA depletion and apoptotic resistance in microsatellite-unstable colorectal cancer. Cancer Res 2011; 71: 2978-2987.

27. Choudhuri S, Chowdhury IH, Das S, Dutta D, Saha A, Sarkar R, Mandal LK, Mukherjee S, Bhattacharya $B$. Role of NF-kappaB activation and VEGF gene polymorphisms in VEGF up regulation in non-

Trop J Pharm Res, June 2017; 16(6): 1265 
proliferative and proliferative diabetic retinopathy. $\mathrm{Mol}$ Cell Biochem 2015; 405: 265-279.

28. Kim SJ, Yoo WS, Choi M, Chung I, Yoo JM, Choi WS. Increased O-GlcNAcylation of NF-kappaB Enhances Retinal Ganglion Cell Death in Streptozotocin-induced Diabetic Retinopathy. Curr Eye Res 2016; 41: 249-257.

29. Mitamura $Y$, Harada T, Harada $C$, Ohtsuka K, Kotake S, Ohno S, Tanaka K, Takeuchi S, Wada K. NF-kappaB in epiretinal membranes after human diabetic retinopathy. Diabetologia 2003; 46: 699-703.

30. Aguirre-Rueda D, Guerra-Ojeda $S$, Aldasoro M, Iradi A, Obrador E, Ortega A, Mauricio MD, Vila JM, Valles SL. Astrocytes protect neurons from Abeta1-42 peptideinduced neurotoxicity increasing TFAM and PGC-1 and decreasing PPAR-gamma and SIRT-1. Int $J$ Med Sci 2015; 12: 48-56. 